\title{
The Effect of Visual Cueing and Control Design on Children's Reading Achievement of Audio E-books with Tablet Computers
}

\author{
Pei-Yu Wang ${ }^{1, *}$ \& Chung-Kai Huang ${ }^{2}$ \\ ${ }^{1}$ Department of e-Learning Design and Management, National Chiayi University, Chiayi County, Taiwan \\ ${ }^{2}$ Department of International Business, National Taipei University of Business, Taipei, Taiwan \\ *Corresponding author: Department of e-Learning Design and Management, National Chiayi University, Chiayi \\ County, Taiwan. Tel: 886-5-226-3411 ext. 1529. E-mail: sweetpeiyu@gmail.com
}

Received: January 8, 2015 Accepted: February 10, 2015 Online Published: March 15, 2015

doi:10.5430/jct.v4n1p96 URL: http://dx.doi.org/10.5430/jct.v4n1p96

\begin{abstract}
This study aims to explore the impact of learner grade, visual cueing, and control design on children's reading achievement of audio e-books with tablet computers. This research was a three-way factorial design where the first factor was learner grade (grade four and six), the second factor was e-book visual cueing (word-based, line-based, and paragraph-based cueing), and the third factor was e-book control mechanism (system-controlled and learner-controlled). The e-books used in this study were on the topic of six major classes of nutrients and the content was created with Adobe Flash CS 5.5. This research was guided by this question: Is there any interaction among learner grade, visual cueing, and learner control on children's reading of audio e-books in terms of learning achievement (recall and transfer)? A sample of one hundred and eighty-five fourth and sixth graders joined the study, and participants were assigned into one of these groups randomly. The results showed significant interactions among these three factors. The fourth graders found the paragraph-based cueing and system-controlled mechanism advantageous; however, the sixth graders performed equally well under all different conditions of interface design. The results indicated that the fourth and sixth graders have different characteristics as readers and, by extension, suggest audio e-book design should consider the target readers' cognitive and psychological development.
\end{abstract}

Keywords: elementary education; human-computer interface; visual-cueing; audio e-books

\section{Introduction}

The use of e-books with tablets for educational purposes has become widespread globally, and the adoption of the technological features has the potential to alter the educational process of teaching and learning (Dündara \& Akçayırb, 2014; Felvégi \& Matthew, 2012). Tablet computers make it possible for students to hold libraries in their hands, and provide students with opportunities to read in different locations at any time with diverse media (Falloon, 2013; Felvégi \& Matthew, 2012; Schreus, 2013). The reading of e-books on tablets has transformed the entire reading process, moving from static printed text to highly interactive text in a variety of formats, software and display options (Felvégi \& Matthew, 2012). Tablet-based e-books support children's emerging literacy development by extending the connections elementary students make with the text through touch-screen manipulation and text-to-speech format. As a result, it is recommended that school teachers use tablets with true curricular integration rather than as add-ons to instruction (Hutchison, Beschorner, \& Schmidt-Crawford, 2012; Larson, 2010; Moody, 2010). A few studies have begun to elaborate on the features of tablet-based e-books that may especially influence children's literacy skills, including font size manipulation, text-to-speech tools, dictionaries, automatic page turning, and animation hotspots. However, some researchers have pointed out that low-quality e-books offered distracting digital features such as overloaded animation, sound unrelated to the story, or inappropriate text-to-speech features (Miller \& Warschauer, 2013; Moody, 2010).

The text-to-speech feature is one advantageous trait of tablet-based e-books over traditional print sources since reading aloud has been found to be one of the most effective forms of teaching children to read (Beck \& Mckeown, 2001). The provision of both audio and textual information is a useful technique in promoting self-learning (Gibson, 2008). Although people often believe that using spoken information simultaneously with the same written text is 
beneficial for learning, available evidence indicates that learning could be inhibited by the presentation of the same verbal information in both modalities (Kalyuga, Chandler, \& Sweller, 1999). This is known as the verbal redundancy effect, which refers to the restrained situation of learning when there is the simultaneous presentation of text and narration with identical words (Kalyuga, 2012). Researchers argued that verbal redundancy effects may occur when learners are required to integrate sources of audio and textual information (Kalyuga, 2012; Kalyuga, Chandler, \& Sweller, 1999; Moreno \& Mayer, 2002). Several strategies, such as asynchronous presentation of sources, use of visual cueing, and learner-controlled design, were presented to solve the verbal redundancy problem to keep the text-to-speech feature working better (Kalyuga, Chandler, \& Sweller, 2004; Kalyuga, 2012). These strategies play important roles in the audio-visual design of e-books; however, few studies have taken an integrative viewpoint by considering more than one strategy. Moreover, limited studies focus on the design of the text-to-speech feature for different ages of young children (Moody, 2010).

This study aims to understand how certain strategies work on the text-to-speech design of audio e-books. The goal of this research is to investigate the impact of visual cueing and control design on the reading of audio books on tablet computers by children in different grades. This study picked one unit from a children's textbook in health education, Six Major Classes of Nutrients, and reworked the content into an audio e-book. This research used e-books as the media for content delivery because e-books have become extensively popular across a range of education levels and subject domains, and studies claim that the multimedia features in e-books help children improve the reading comprehension skills (Grimshaw, Dungworth \& Mcknight, 2007). The goal of this study is to compare learning achievement among e-books with different visual cueing strategy design (word-based, line-based, and paragraph-based) and control mechanisms (system-controlled and learner-controlled) for the fourth and sixth graders, and considers how children's grade level influences the use of audio books. The research question is: Is there any interaction among grade, visual cueing, and learner control on children's reading of audio books in terms of learning achievement (recall and transfer)? A brief theoretical background is presented in the following section to better understand the relative factors before diving into the experimental design to address this question.

\section{Theoretical Background}

\subsection{Verbal Redundancy Effect}

The design of audio e-books' text-to-speech feature is closely related to the dual processing model theory (Paivio, 1971), and previous empirical studies on multimedia modalities could serve as important references (Kalyuga, 2012; Mayer, 2009). A dual-processing model of memory (also known as the dual coding theory) considers working memory capacities to be distributed over separate verbal (including speech and text) and visual channels (Paivio, 1971 ; 1986). Baddeley (1986) then expanded the dual coding theory by dividing the working memory into a phonological loop and a visual-spatial sketchpad. The phonological loop processes auditory information (including visually presented language) whereas the visual-spatial sketchpad deals with visual information such as diagrams and pictures. Since speech and text go into the same verbal channel, learners might be cognitively overloaded if the two sources of information are presented at the same time (Kalyuga, Chandler, \& Sweller, 2004). When reading an audio e-book, learners may not be able to temporally and spatially synchronize the media and may not be able to determine exactly what within the visual content and the sound content is important. In such cases, not only will the auditory and visual channels fail to interact but learners will also have to use a considerable amount of cognitive resources to determine where the audio and texts should be synchronized. As a result, a considerable amount of content comprehension is lost (Kalyuga, 2012). This is known as verbal redundancy effect and several studies have reported the existence of this effect. Kalyuga, Chandler and Sweller $(1999 ; 2004)$ used lengthy technical textual materials without any visual aids included to demonstrate a verbal redundancy effect. They observed that the addition of concurrent audio explanations to texts had a negative effect on learning. Mayer (2009) argued that concurrent on-screen texts animations and narrations overloaded the verbal channel because of competition between the two verbal sources (texts and audio) for cognitive resources. Although processing both auditory and textual material may overload working memory and decrease learning outcomes, researchers have been looking for approaches to improve audio-visual design and optimize the integration of information through different modalities. Several strategies were presented to solve the verbal redundancy problem to direct learner attention and improve information integration, thus causing the text-to-speech feature to work better (Kalyuga, Chandler, \& Sweller, 2004; Kalyuga, 2012). One common solution to this problem is to use visual cueing. The following section discusses the use of visual cueing in the multimedia learning environment. 


\subsection{Visual Cueing}

Visual cueing refers to the addition of non-content information (eg. pointers, arrows, circles, and colors) to visual representations (Ando \& Ueno, 2008; Lin \& Atkinson, 2011). Visual cues highlight the key points of instructional materials and thus guide attention, reducing visual search and extraneous cognitive load and enhancing source integration in a multimedia learning environment (deKoning, Tabbers, Rikers, \& Paas, 2010). From a cognitive load perspective, visual cueing is an effective method to reduce extraneous load in the multimedia learning environment and is helpful to the processing of audio and text. Several studies have supported the instructional benefits of visual cueing (de Koning, Tabbers, Rikers, \& Pass, 2010; Jamet, Gavota, \& Quaireau, 2008; Lin \& Atkinson, 2011). Researchers have argued that learners had higher comprehension and transfer scores in a cued animation with spotlight effect cues (de Koning, Tabbers, Rikers, \& Pass, 2010). Lin \& Atkinson (2011) used arrows as visual cues and claimed that learners displayed more instructional efficiency (retained more concepts but spent less time) than uncued peers. Jamet, Gavota, \& Quaireau (2008) used a coloring technique as a visual cue and suggested that learners performed better with saliently colored material. Some researchers looked for more advanced visual cueing designs to improve learning efficiency. For example, in de Koning et.al's (2010) study, visual cues were designed and categorized as small-scale single cue and large-scale multiple cues for learning efficiency comparison. Although no clear effects occurred in that experiment, it broadened the possibilities of research issues on the design approach of visual cueing.

This study was inspired by Jamet et al.'s (2008) study where the coloring technique was chosen as the visual cueing strategy, and de Koning et al.'s (2010) study of comparisons for diverse cueing scales. We recorded voice narration of the text for the e-book and each part of the text was colored to correspond with the narrators' voice. We then designed visual cues as three types: word-based cueing, line-based cueing, and paragraph-based cueing. Each type of cueing addresses a different length of textual scale to be colored in sync with the narration.

\subsection{Control Design}

The term learner control is used to describe if learners have multiple ways of interacting with instructional materials, such as sequencing, selection of content, representation, and pacing (Scheiter \& Gerjets, 2007). In this study, it refers to the design of reading options, enabling the buttons to go forward, backward or restart. Some researchers have argued that a learner-controlled program increases learning outcomes because of its adaptation to preferences and cognitive needs, and its affordances for constructive and deeper information processing (Merrill, 1980; Patterson, 2000; Scheiter \& Gerjets, 2007). However, some researchers have claimed that the learner-control mechanism benefits adults but is not helpful for young children who are not well-prepared for self-learning (Johnson, Perry, and Shamir, 2010). Studies show that the control design may mediate the outcomes of learning integration of audio and visual sources. Ginn's meta-analysis of the modality effect (2005), which targeted forty-two cases of relevant research, argued that learners' integration of auditory and visual sources is moderated by learner control (eg. pacing of the presentation). That is, learners' integration of two information sources was different in studies where the pace was set by the system from those studies in which readers controlled their own pace (Ginns, 2005). However, among the forty-three cases in Ginns' study, none targeted elementary learners as participants. The understanding of the control design on children's learning of visual-audio material is limited.

\subsection{Children's Development of Information Processing and Integration}

The effects of audio-visual instruction found in adults may be different from those in children. Theorists have proposed that there are age changes in children's cognitive development and information processing (Bruner, 1964; Perlmutter \& Myers, 1975; Rohwer, 1970; Shaffer, 2002). Researchers argue that motor representation precedes visual representation, which in turn precedes verbal information (including textual and auditory information) (Bruner, 1964; Rohwer, 1970). It is not until the age of five that visual coding becomes more efficient, and then children start to develop the verbal coding ability (Perlmutter \& Myers, 1975). During the elementary school stage, children's verbal and visual coding ability continue developing and the memory capacity keeps on expanding. Also, the ability of linking visual, textual and audio channels and the strategy to switch and integrate different channels is developing. The cognitive development of the human brain is not fully developed until late adolescence and in some males not until early adulthood (Case, 1985). Children are not able to fully take advantage of the audio-visual instruction, and this might be due to several reasons. First, children may have inadequate attentional control towards learning materials (Mann, Schulz, \& Cui, 2011). Educational multimedia require children to actively listen and read instructional content, and mentally articulate the meaning in the text and audio; however, children may not be able to consciously focus their attention to bind the separate stimulus into a unitary object (Matlin, 2002). Second, children may have an under-developed phonological loop (Mann, Schulz, \& Cui, 2011). The phonological loop as a whole 
deals with sound or phonological information, and plays a crucial role in the acquisition of the phonological form of lexical items (Baddeley, 1986). Adults are able to listen to a sound presented in multimedia and encode the gist directly into their phonological store, encoding the details indirectly through their articulatory loop. Children are not fully capable of articulating difficult or unfamiliar content presented in text and audio. Their auditory memory consists of a phonological store without a phonological loop (Mann, Schulz, \& Cui, 2011). Unarticulated material in young children is analogous to extraneous cognitive load, and they need more aids to better articulate different sources of information (Kalyuga, Chandler, \& Sweller, 1999).

This study selected the fourth and sixth graders as participants because they represent different stages of psychological and literacy development in late childhood (Su \& Samuels, 2010). The sixth graders, whose age ranges from twelve to thirteen, are approaching the formal operational stage (adolescence and into adulthood) with a well-developed cognitive ability and phonological loop (Piaget, 1970). The cognitive development in this stage becomes stable and individual differences are smaller when compared with the fourth graders. The sixth graders have better cognitive ability such as attention, reasoning and organizing, and are more capable of utilizing strategies to solve problems in the learning process (Piaget, 1970; Justice, 1985; Shaffer, 2002).

For the fourth graders, these students have just reached a basic literacy threshold, by which one is just able to read individually and independently (Wang, Hung, Chang, Chen, 2008). Based on Chall's model (2003), the fourth graders read not only to learn to recognize words, but begin to learn new knowledge, information, thoughts, and experiences. Reading in this stage shifts from "learning to read" to "reading to learn." This change requires learners to read texts with the inclusion of a more extensive vocabulary, a heavier content load and a need for more background knowledge and learning strategies (Chall \& Jacobs, 2003). From the developmental psychologist's viewpoint, learners in this grade are in a particular concrete operational stage (Piaget, 1970; Shaffer, 2002). Most students still lack of the ability to utilize and activate strategies for information processing and integration (Guttentag, Ornstein, \& Siemansm 1987; Justice, 1985; Justice, Baker-Ward, Gupta, \& Jannings, 1997). Due to the increasingly complex reading task but having an underdeveloped cognitive ability as well as phonological loop, students in this stage can easily find themselves in a "fourth grade slump," which refers to the situation when students fall behind in reading in their fourth grade (Chall \& Jacobs, 2003). The fourth grade slump problem will disappear as the child gets older. Theoretically, the needs for the fourth graders are particularly different from those of the sixth graders, who are more mature readers and whose reading capabilities and cognitive abilities are more like those of young adults. Due to the difference of cognitive and literacy development, the children's response and need for the audio e-books may be different. Thus, this study aims to address this issue and explore the appropriate design approach of audio e-books to meet the needs of student in these two grades.

\section{Method}

\subsection{Design and Development of an Audio E-book for Six Major Classes of Nutrients}

\subsubsection{Program Design and Development}

Adobe Flash CS5.5 Professional and Action Script 3.0 were used to create the audio e-book. This program was designed with an $841 \mathrm{px} * 595 \mathrm{px}$ window (A4 size). The screen size made it possible for the installation of the audio e-book program on mobile devices. In this study, tablet computers were the primary device used. For the needs of this particular study, this audio e-book was developed into several versions using the same story. The following treatment section shows snapshots of these designs.

\subsection{Research Questions}

This research aimed to explore the impact of visual cueing and control design on different graders' reading achievement of audio books on tablet computers. This research was a three-way factorial design. The first factor was learner grade in two levels: (1) fourth grade, and (2) sixth grade; the second factor was e-book visual cueing in three levels: (1) word-based, (2) line-based, and (3) paragraph-based cueing; the third factor was e-book control mechanism in two levels: (1) system-controlled, and (2) learner-controlled. The dependent variables include: (1) recall scores, and (2) transfer scores. The research questions were: (1) Is there any interaction among learner grade, visual cueing and control design in children's learning recall?; (2) Is there any interaction among learner grade, visual cueing and control design in children's learning transfer?

\subsection{Participants}

The experiment was carried out in the spring semester in 2014. Participants were invited from one elementary school 
in Taiwan. There were one hundred and eighty-five participants joined this study; eighty-seven were the fourth graders and ninety-eight were the sixth graders; eighty-eight (48\%) were female and ninety-seven (52\%) were male. Participants were randomly assigned into groups and the size of each group ranged from 11 to 19 depending on the learner grade.

\subsection{Treatment}

As mentioned above, there were several versions of the audio e-book with different levels of visual cueing and control, and students were randomly assigned into one of the different treatment groups. As to the visual cueing design, there were three types of visual cueing: (1) word-based cueing, (2) line-based cueing, and (3) paragraph-based cueing. The three visual cueing versions were designed by taking into consideration that the three levels of exposure (word, line, or paragraph) by text highlighting. In each design, the text was colored differently to accompany the narrators' reading. Figure 1 shows snapshots of the visual cueing for the three versions of the audio e-books. As to the control design, there were two types of control: (1) system-controlled and (2) learner-controlled. The audio e-book with the learner-controlled mechanism allowed learners to navigate backward, forward, and restart, whereas the audio e-book with the system-controlled mechanism did not. The audio e-book with the system-controlled mechanism only allowed learners to go sequentially with the order set by the system. Figure 2 shows snapshots of the control design for the two versions of the audio e-books.
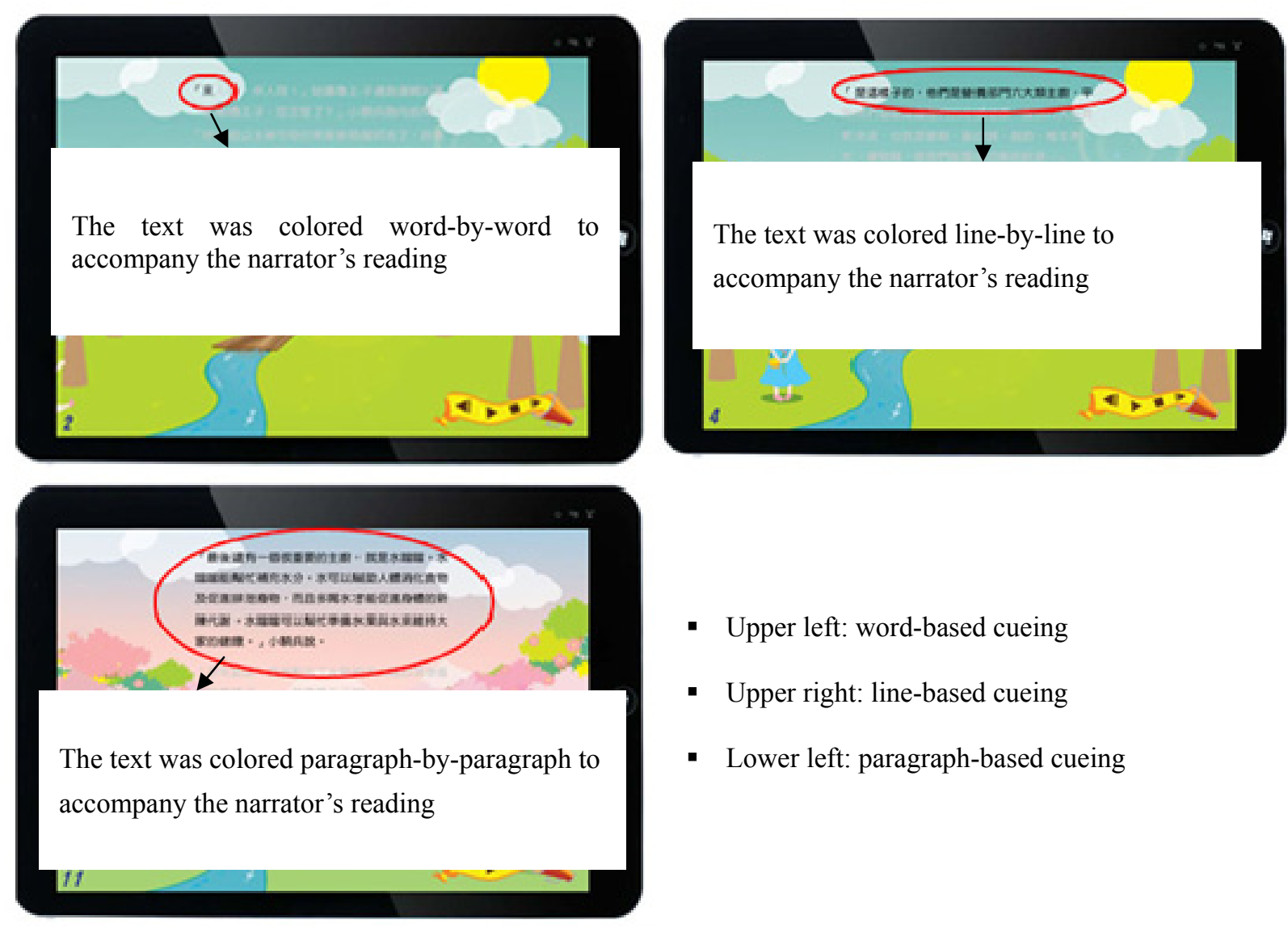

- Upper left: word-based cueing

- Upper right: line-based cueing

- Lower left: paragraph-based cueing

Figure 1. Snapshots of the Visual Cueing for the Versions of the Audio E-Books 


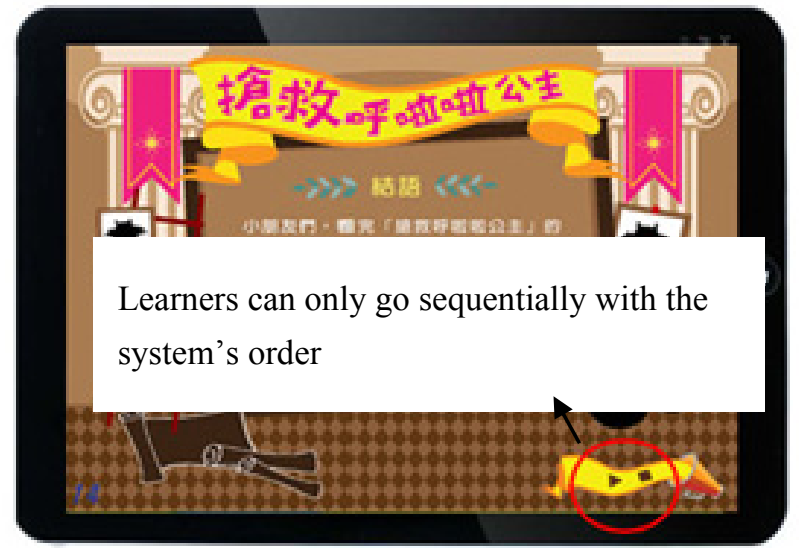

Left: System-controlled

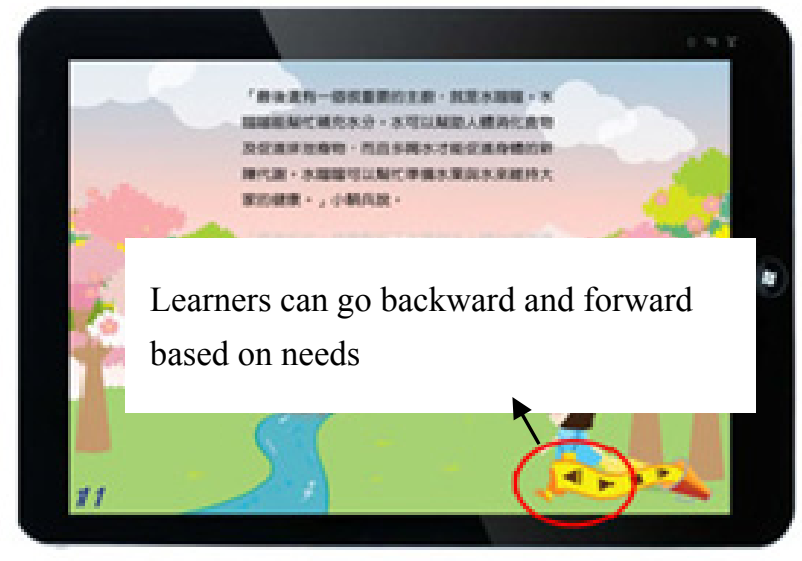

Right: Learner-controlled

Figure 2. Snapshots of the Control Design for Two Versions of the Audio E-Books

\subsection{Instruments}

The achievement tests (consisting of a pretest a posttest) were designed with twelve multiple-choice questions for recalling and one matching question for transferring. These two types of questions were used to examine the two different cognitive dimensions of learning (recall and transfer). All questions were created to test students' knowledge of the six major classes of nutrients. One sample question for recalling is: What nutrient do milk, eggs, fish, and beans contain in common? One sample question for transferring is: Mary was diagnosed by the doctor as having symptoms of anemia. Which kind of food do you suggest Mary eat to fight the disease? The pretest and posttest were composed of similar questions, comparable in difficulty level and format. On both tests, each student had two separate scores (recall and transfer) for achievement. An experienced elementary school teacher and a nutritionist verified the test questions for expert validity.

\subsection{Experimental Procedures}

The pretest was conducted two weeks before the experiment to understand learners' prior knowledge. Then during the experiment, we randomly assigned students to one group and ask students to read e-books by individual. Students need to complete the reading task on tablet computers along with the posttest in a computer lab. We gave students twenty minutes to do the reading task and the whole experiment was in one hour.

\section{Results}

There was no significant between-group difference in any aspect of the student pretest for the fourth and sixth graders respectively, which means students in the two grades had equal starting points for learning. However, differences occurred in the posttest scores. The descriptive statistics for the pretest and posttest scores are as follows (Table 1). 
Table 1. Descriptive Statistics on Learning Outcome for Each Group

\begin{tabular}{|c|c|c|c|c|c|c|c|c|c|c|}
\hline & & & Recall & etest & Transf & retest & Recall & osttest & Transfe & osttest \\
\hline Grade & Control design & Visual cueing & Mean & $S D$ & Mean & $S D$ & Mean & $S D$ & Mean & $S D$ \\
\hline \multirow{6}{*}{4} & \multirow{3}{*}{$\begin{array}{l}\text { System- } \\
\text { controlled }\end{array}$} & Word-based & 4.67 & 1.28 & 3.06 & 1.00 & 6.06 & 1.31 & 3.50 & 1.30 \\
\hline & & Line-based & 5.57 & 1.79 & 3.00 & 1.52 & 7.00 & 1.20 & 3.43 & 1.28 \\
\hline & & Paragraph-based & 5.36 & 1.12 & 3.00 & 1.79 & 7.55 & 1.44 & 4.18 & 1.08 \\
\hline & \multirow{3}{*}{$\begin{array}{l}\text { Learner- } \\
\text { controlled }\end{array}$} & Word-based & 4.89 & 1.45 & 3.11 & 1.45 & 6.39 & 1.72 & 3.61 & 1.58 \\
\hline & & Line-based & 5.00 & 1.16 & 3.15 & 1.35 & 6.31 & 1.49 & 4.15 & 1.63 \\
\hline & & Paragraph-based & 4.92 & 1.19 & 3.69 & 1.18 & 5.77 & 1.54 & 4.23 & 1.09 \\
\hline \multirow{6}{*}{6} & \multirow{3}{*}{$\begin{array}{l}\text { System- } \\
\text { controlled }\end{array}$} & Word-based & 4.00 & 1.58 & 3.65 & 1.62 & 6.29 & 1.86 & 4.29 & 1.11 \\
\hline & & Line-based & 4.20 & 2.00 & 3.27 & 1.22 & 7.53 & 1.77 & 3.93 & 1.10 \\
\hline & & Paragraph-based & 4.89 & 1.41 & 3.78 & 1.52 & 6.61 & 1.61 & 4.17 & 1.54 \\
\hline & \multirow{3}{*}{$\begin{array}{l}\text { Learner- } \\
\text { controlled }\end{array}$} & Word-based & 4.26 & 1.45 & 3.53 & 1.93 & 6.95 & 1.78 & 3.74 & 2.00 \\
\hline & & Line-based & 4.50 & 1.61 & 3.57 & 1.45 & 6.21 & 2.08 & 4.07 & 1.44 \\
\hline & & Paragraph-based & 4.20 & 1.78 & 3.87 & 1.69 & 7.40 & 1.88 & 4.40 & 1.45 \\
\hline & Mean & & 4.70 & 1.48 & 3.38 & 1.48 & 6.65 & 1.66 & 3.96 & 1.39 \\
\hline
\end{tabular}

Note. Total score for recall was 10; total score for transfer was 6 .

\subsection{Recall scores}

Before conducting the three-way ANOVA analysis to understand interactions, this study did an analysis to understand which combination of the visual design and control design performed best. Six combinations were generated and tested in the study (system controlled with word-based cueing, learner controlled with word-based cueing, system controlled with line-based cueing, learner controlled with line-based cueing, system controlled with paragraph-based cueing, learner controlled with paragraph-based cueing). For the fourth graders, significant difference existed among these groups $\left(F(5,81)=2.40, p=.04, \eta^{2}=.13\right)$. The post hoc results show that students in the paragraph-based cueing group with the system-controlled design performed significantly better than all other groups. For the sixth graders, no significant difference existed among the six groups in terms of learner recall $\left(F(5,92)=1.42, p=.23, \eta^{2}=.07\right)$.

Subsequently a three-way ANOVA was conducted to understand interactions among the factors. The results showed significant interactions among grade, visual cueing and learner control $\left(F=3.36, p<.05, \eta^{2}=.04\right)$. To explore the nature of the interactions, tests of the simple interaction effects were performed (Table 2). In the simple interaction effect analysis, the results show the following significant interactions: 1) Interactions between visual cueing and control design existed among the fourth grade students $\left.\left(F=3.69, p=.03, \eta^{2=} .08\right) ; 2\right)$ Interactions between learner grade and control design existed among students using the paragraph-based cueing e-books $\left(F=8.41, p=.01, \eta^{2=} .14\right)$.

Table 2. Results of Simple Interaction Effect

\begin{tabular}{lllllll}
\hline Source of Variance & $S S$ & $d f$ & $M S$ & $F$ & $p$ & $\eta^{2}$ \\
\hline Visual cueing * Learner control & & & & & & \\
$\quad$ Within fourth graders & 16.114 & 2 & 8.057 & 3.69 & $\mathbf{. 0 3}^{*}$ & .08 \\
$\quad$ Within sixth graders & 21.21 & 2 & 10.60 & 3.18 & .05 & .07 \\
\hline Grade * visual cueing & & & & & & \\
$\quad$ Within system-controlled group & 8.51 & 2 & 4.26 & 1.72 & .19 & .04 \\
$\quad$ Within self-controlled group & 10.46 & 2 & 5.23 & 1.68 & .19 & .04 \\
\hline Grade* learner control & & & & & & \\
$\quad$ Within word-based group & .46 & 1 & .46 & .16 & .69 & .00 \\
$\quad$ Within line-based group & 1.37 & 1 & 1.37 & .48 & .49 & .01 \\
$\quad$ Within paragraph-based group & 22.69 & 1 & 22.69 & 8.41 & $.011^{*}$ & .14 \\
\hline$<.05 \quad$ & & & & & &
\end{tabular}

Further analysis of the two interactions was performed. As to the interaction between visual cueing and control design which existed among the fourth graders, the results of the further analysis are presented in Table 3. In the fourth grade group, the students in the paragraph-based cueing design group had significantly better scores than students in the word-based cueing design group $\left(F=4.61, p=.02, \eta^{2=} .19\right)$. In addition, for the same fourth grader 
group, while reading an e-book with paragraph-based cueing design, students with the system-controlled mechanism had significant better scores than students with the learner-controlled mechanism $\left(F=8.43, p=.01, \eta^{2=} .28\right)$.

Table 3. Results of the Visual Cueing * Control Design Interaction for the Fourth Grade Group

\begin{tabular}{lccccccc}
\hline Source of Variance & $S S$ & $d f$ & $M S$ & $F$ & $p$ & $\eta^{2}$ & Post Hoc \\
\hline Control & & & & & & & \\
$\quad$ In system controlled & 16.51 & 2 & 8.26 & 4.61 & $\mathbf{. 0 2}^{*}$ & .19 & Paragraph $>$ word \\
$\quad$ In learner controlled & 3.19 & 2 & 1.60 & .62 & .54 & .03 & \\
\hline Visual cueing & & & & & & & \\
$\quad$ In word-based group & 1.00 & 1 & 1.00 & .43 & .52 & .01 & \\
$\quad$ In line-based group & 3.23 & 1 & 3.23 & 1.66 & .21 & .06 & \\
$\quad$ In paragraph-based group & 18.80 & 1 & 18.80 & 8.43 & $\mathbf{. 0 1}^{*}$ & .28 & $\begin{array}{c}\text { System controlled }> \\
\text { learner controlled }\end{array}$ \\
\hline$*<.05$ & & & & & & &
\end{tabular}

In the paragraph-based cueing group, the sixth graders had significantly better scores than the fourth graders when the e-book was learner-controlled $\left(F=6.18, p=.02, \eta^{2=}\right.$.19). In addition, for the same paragraph-based cueing group, the fourth graders had significantly better scores when the e-book was system-controlled compared to learner-controlled $\left(F=8.43, p=.01, \eta^{2=} .28\right)$ (Table 4$)$.

Table 4. Results of the Grade * Control Design Interaction for the Paragraph-Based Cueing E-Book Group

\begin{tabular}{|c|c|c|c|c|c|c|c|}
\hline Source of Variabce & SS & $\mathrm{df}$ & MS & $\mathrm{F}$ & $\mathrm{p}$ & $\eta^{2}$ & Post Hoc \\
\hline \multicolumn{8}{|l|}{ Grade } \\
\hline Within fourth graders & 49.04 & 1 & 18.80 & 8.43 & $.01^{*}$ & .28 & $\begin{array}{l}\text { System controlled }> \\
\text { learner controlled }\end{array}$ \\
\hline Within sixth graders & 5.09 & 1 & 5.09 & 1.68 & .20 & .05 & \\
\hline \multicolumn{8}{|l|}{ Control } \\
\hline Within system controlled & 5.96 & 1 & 5.96 & 2.48 & .13 & .08 & \\
\hline Within learner controlled & 18.52 & 1 & 18.52 & 6.18 & $.02^{*}$ & .19 & sixth $>$ fourth \\
\hline
\end{tabular}

For the transfer scores, the ANOVA showed that the three-way interaction among grade, visual cueing and control design was not significant $(F=.45, p>$. 05). In addition, there existed no significant two-way interaction effects among these factors.

\section{Discussion}

This study explored the interactions among visual cueing, control design and children's grade level on the reading of audio e-books on tablet computers in terms of learning achievement. The results showed that interactions existed in learner recall but not in learner transfer. The insignificance of transfer scores might be associated with the short learning time in the experiment (only twenty minutes). Learners had a limited time slot to absorb new knowledge and engage themselves in higher linkage, integration and advanced application. Regarding the recall scores analyzed in the one-way or three-way ANOVA, the study had two important findings: (1) For the fourth graders, the combination of paragraph-based cueing and system-controlled mechanism best enhanced their recall; (2) The cueing and control design did not significantly impact the sixth graders' recall at all.

In terms of the cueing design, for young learners (the fourth graders) who are in the concrete operation stage as well as the "fourth -grade slump" phase, the word-based cueing design might generate more cognitive load due to learners' under-developed phonological loop, limited memory capacity, and restrained information linkage and processing strategy. In the word-based cueing design, the audio and the text were presented exactly at the same time, and learners had to listen to the audio of each word and watch texts simultaneously. Students spent all their efforts matching sounds to words, but understood nothing of the delivered content. The information delivered was not truly articulated and meaningful to learners during the reading process. In case of the paragraph-based cueing design, students did not have to catch textual information word by word. They could read the words at their own pace, and 
the visual marking became a reminder to tell learners where the narrator was. Moreover, in the paragraph-based cueing design, it was possible for learners to rely on only visual information or auditory information since the narration appeared after the text turned color. Since the text and audio were not shown at the exact same time, learners may have taken advantage of only one of the channels. For the design of paragraph-based visual cueing, the non-concurrent presentation of identical information sources did not exceed working memory capacity, and thus increased the effectiveness of learning. The visual cueing effect disappeared as learner age increased. In this study, the cueing design did not make any significant difference to the sixth graders. The sixth graders had a better phonological loop, better learning strategies, and even more background knowledge to integrate information from different sources, and consequently the cueing design might no longer have played a critical role in their reading of audio e-books.

In terms of the controlled design, this study shows that the fourth graders had better recalling scores with the system-controlled mechanism, but the sixth graders performed equally in all conditions. The audio e-book with the learner-controlled mechanism allowed learners to navigate in a flexible way using the backward, forward, and restart buttons, whereas students in the system-controlled group could only read the audio e-book in a linear way and they had to move on with the order and pace of the system. Several arguments claim that interactive learner-controlled environments may lead adults to better results, including adaptation to preferences and cognitive needs, and affordances for constructive and deeper information processing (Merrill, 1980; Patterson, 2000; Scheiter \& Gerjets, 2007). However, an increasing number of studies suggest that the learner-controlled mechanism was not that helpful for elementary learners who have little experience with digital learning environments and reading tutorials on computers (Johnson, Perry, \& Shamir, 2010; Schwarz, Anderson, Hong, Howard, \& MaGee, 2004; Wang, \& Yang, 2014). Wang \& Yang's (2014) study shows that for 10-year-old elementary learners (the fourth graders), the use of a simple linear sequence is still better than an interactive learner-controlled mechanism in a digital reading environment. Young learners tend to benefit from a comparatively simple, non-linear and system-control design due to the lack of attentional control and meta-cognitive abilities (de Jong, 2004; Pearman \& Chang, 2010; Wang, 2014), and the benefit of the system-controlled mechanism might change as they increase in age and mature cognitively and psychologically. In this study, the advantage of the system-controlled environment did not exist for the sixth grade students. The age of the sixth graders ranged from eleven to twelve, which is in Piaget's formal operations stage. Learners in this stage were more cognitively well-developed and capable of doing abstract thinking, reasoning and conducting information linkage (Piaget, 1970; Justice, 1985; Shaffer, 2002). Also, the problem-solving ability and learning strategies used were comparatively better for the sixth graders than the fourth graders (Piaget, 1970; Shaffer, 2002). The sixth graders were more able to take advantage of the forward, backward, and replay functions to facilitate information integration. With children's increasing maturity in cognitive, psychological and language development, the role of the learner-control mechanism becomes comparatively important in the reading process.

The needs for the fourth graders are different from those of the sixth graders who are more mature readers and whose reading capabilities and abilities in their native language (Chinese) are more like those of young adults, and this explains why the fourth graders and sixth graders performed differently in certain groups. The educators and researchers should take learner cognitive development into consideration, especially for young children, while designing audio e-books.

\section{Conclusion}

The results showed interactions among visual cueing, control design, and learner grade on learner recall. The fourth graders found the paragraph-based cueing and system-controlled mechanism advantageous. Different from the fourth graders' better performance with a system-controlled mechanism, the sixth graders performed equally well under all different interface conditions.

This study was restricted by the following limitations. First, this study targeted six major classes of nutrients as the content matter. The knowledge nature of this unit is basically factual and conceptual instead of procedural or metacognitive. High level of mental operation or reasoning is not necessary in this case. Consequently, the results might be different if the content matter is changed to other subjects with different cognitive levels. Second, the research was carried out in a computer laboratory with only a short period of timeslot, students' reading motivation and performance might be dissimilar from that in a real classroom learning environment. Although these limitations may not allow over generalization to broad processes of learning in other subjects, reporting this work is still valuable due to the practical suggestions to children's audio e-book designs and its attempt to expand multimedia learning theory. 
Future research might address the exploration of the effect in a real-world classroom with instructional strategies instead of in a laboratory, as well as the revision of current instruments and creation of new measurement to better understand learner responses to different designs of audio e-books. In addition, the use of eye-trackers can be considered for future study to better explore learners' visual processing of texts, and qualitative analysis will be conducted to seek in-depth understanding of learner behavior and learning outcomes.

In summary, to make audio e-books work better, the learner's cognitive capability must be considered. Children at different grade levels may need different ways of visual cueing design as well as control design, and instructors need to assess whether the audio e-book is accessible for young learners at different developmental stages. To advance the understanding of the affordances and constraints of text-to-speech features for children's learning, relevant empirical studies on multimedia design are needed to substantially expand our knowledge on the instructional promises and perils.

\section{References}

Ando, M., \& Ueno, M. (2008). Effect of pointer presentation on multimedia e-learning materials. In J. Luca \& E. Weippl (Eds.), Proceedings of World Conference on Educational Multimedia, Hypermedia and Telecommunications 2008 (pp. 5549-5559). Chesapeake, VA: AACE.

Baddeley, A.D. (1986). Working memory. New York: Oxford University Press.

Beck, I.L., \& Mckeown, M.G. (2001). Text talk: Capturing the benefits of read-aloud experiences for young children. The Reading Teacher, 55, 10-20.

Bruner, J.S. (1964). The course of cognitive growth. American Psychologist, 19, 1-15. http://dx.doi.org/10.1037/h0044160

Case, R. (1985). Intellectual development: Birth to adulthood. New York: Academic Press.

Chall, J. S., \& Jacobs, V. A. (2003). The classic study on poor children's fourth -grade slump. American Educator, 27(1), 14-17.

de Jong, M.T., \& Bus, A.G. (2004). The efficacy of electronic books in fostering kindergarten children's emergent story understanding. Reading Research Quarterly, 39(4), 378-393. http://dx.doi.org/10.1598/RRQ.39.4.2

de Koning, B. B., Tabbers, H. K., Rikers, R. M. J. P., \& Paas, F. (2010). Attention guidance in learning from a complex animation: Seeing is understanding? Learning and Instruction, 20(2), 111-122. http://dx.doi.org/10.1016/j.learninstruc.2009.02.010

Dündara, H., \& Akçayırb, M. (2014). Implementing tablet PCs in schools: Students' attitudes and opinions. Computers in Human Behavior, 32, 40-46. http://dx.doi.org/10.1016/j.chb.2013.11.020

Falloon, G. (2013). Young students using iPads: App design and content influences on their learning pathways. Computers and Education, 68, 505-521. http://dx.doi.org/10.1016/j.compedu.2013.06.006

Felvégi, E., \& Matthew, K.I. (2012). eBooks ad literacy in K-12 schools. Computers in the Schools, 29, 40-52. http://dx.doi.org/10.1080/07380569.2012.651421

Gibson, S. (2008). Reading aloud: A useful learning tool? English Learning Teaching Journal, 62(1), 29-36. http://dx.doi.org/10.1093/elt/ccm075

Ginn, P. (2005). Meta-analysis of modality effect. Learning and Instruction, 15, 313-331. http://dx.doi.org/10.1016/j.learninstruc.2005.07.001

Grimshaw, S. Dungworth, N., McKnight, C., \& Morris, A. (2007). Electronic books: Children's reading and comprehension. British Journal of Educational Technology, 38(4), 583-599. http://dx.doi.org/10.1111/j.1467-8535.2006.00640.x

Guttentag, R.E., Ornstein, P.A., \& Seimans, L. (1987). Children's spontaneous rehearsal: Transitions in strategy acquisition. Cognitive development, 2, 307-326. http://dx.doi.org/10.1016/S0885-2014(87)80010-2

Hutchison, A., Beschorner, B., \& Schmidt-Crawford, D. (2012). Exploring the use of the iPad for literacy learning. Reading Teacher, 66(1), 15-23. http://dx.doi.org/10.1002/TRTR.01090

Jamet, E., Gavota, M., \& Quaireau, C. (2008). Attention guiding in multimedia learning. Learning and Instruction, 18, 135-145. http://dx.doi.org/10.1016/j.learninstruc.2007.01.011 
Johnson, E.P., Perry, J., \& Shamir, H. (2010). Variability in reading ability gains as a function of computer-assisted instruction method of presentation. Computers and Education, 55, 209-217. http://dx.doi.org/10.1016/j.compedu.2010.01.006

Justice, E.M. (1985). Categorization as a preferred memory strategy: Developmental changes during elementary school. Developmental Psychology, 21(6), 1105-1110. http://dx.doi.org/10.1037/0012-1649.21.6.1105

Justice, E.M., Baker-Ward, L., Gupta, S., \& Jannings, L.R. (1997). Means to the goal of remembering: Developmental changes in awareness of strategy use-performance relations. Journal of Experimental Child Psychology, 65, 293-314. http://dx.doi.org/10.1006/jecp.1997.2368

Kalyuga, S. (2012). Instructional benefits of spoken words: A review of cognitive load factors. Educational Research Review, 7, 145-159. http://dx.doi.org/10.1016/j.edurev.2011.12.002

Kalyuga, S., Chandler, P., \& Sweller, J. (1999). Managing split-attention and redundancy in multimedia instruction. Applied Cognitive Psychology, $\quad$ 351-371. http://dx.doi.org/10.1002/(SICI)1099-0720(199908)13:4<351::AID-ACP589>3.0.CO;2-6

Kalyuga, S., Chandler, P., \& Sweller, J. (2004). When redundant on-screen text in multimedia technical instruction can interfere with learning. Human Factors, 46, 567-581. http://dx.doi.org/10.1518/hfes.46.3.567.50405

Larson, L.C. (2010). Digital readers: The next chapter in e-book reading and response. The Reading Teacher, 64(1), 15-22. http://dx.doi.org/10.1598/RT.64.1.2

Lin, L., \& Atkinson, R.K. (2011). Using animations and visual cueing to support learning of scientific concepts and processes. Computers and Education, 56, 650-658. http://dx.doi.org/10.1016/j.compedu.2010.10.007

Mann, B., Newhouse, P., Pagram, J., Campbell, A., \& Schulz, H. (2002). A comparison of temporal speech and text cueing in educational multimedia. Journal of Computer Assisted Learning, 18, 296-308. http://dx.doi.org/10.1046/j.0266-4909.2002.00241.x

Mann, B., Schulz, H., \& Cui, J. (2011). Speech cueing on the Web by the 'little dude': Multimedia instruction for young children. International Journal of Online Pedagogy and Course Design, 2(3), 32-44.

Mayer, R.E. (2009). Multimedia learning ( $2^{\text {nd }}$ Ed.) New York, NY: Cambridge University Press. http://dx.doi.org/10.1017/CBO9780511811678

Merrill, M.D. (1980). Learning control in computer based learning. Computers and Education, 4, 77-97. http://dx.doi.org/10.1016/0360-1315(80)90010-X

Miller, E.B., \& Warschauer, M. (2014). Young children and e-reading: research to date and questions for the future. Learning, media, and technology, 39(3), 283-305. http://dx.doi.org/10.1080/17439884.2013.867868

Moody, A., K. (2010). Using electronic books in the classroom to enhance emergent literacy skills in young children. Journal of Literacy and Technology, 11(4), 22-52.

Moreno, R., \& Mayer, R. E. (2002). Verbal redundancy in multimedia learning: When reading helps listening. Journal of Educational Psychology, 94, 156-163. http://dx.doi.org/10.1037/0022-0663.94.1.156

Paivio, A. (1971). Imagery and verbal processes. Oxford, England: Holt, Rinehart \& Winston.

Paivio, A. (1986). Mental representations: A dual-coding approach. New York: Oxford University Press.

Patterson, N.G. (2000). Hypertext and the changing roles of readers. English Journal, 90, 74-80. http://dx.doi.org/10.2307/821221

Pearman, C.J., \& Chang, C. (2010). CD-ROM storybooks and young readers. TechTrends, 54(4), 52-56. http://dx.doi.org/10.1007/s11528-010-0420-5

Perlmutter, M., \& Myers, N.A. (1975). Young children's coding and storage of visual and verbal material. Child development, 46, 215-219. http://dx.doi.org/10.2307/1128851

Piaget, J. (1970). Piaget's theory. In P.H. Mussen (Ed.), Carmichael's manual of child psychology (Vol.1). New York: Wiley.

Rohwer, W.D. (1970). Images and pictures in children's learning: research results and educational implications. Psychological Bulletin, 73, 393-403. http://dx.doi.org/10.1037/h0029184

Scheiter, K., \& Gerjets, P. (2007). Learner control in hypermedia environments. Educational Psychology Review, 19, 285-307. http://dx.doi.org/10.1007/s10648-007-9046-3 
Schreus, K. (2013). Children's e-books are born: how e-books for children are leading e-book development and redefining the reading experience. Partnership: The Canadian Journal of Library and Information Practice and Research, 8(2), 1-14.

Schwartz, N.H., Anderson, C., Hong, N., Howard, B., \& McGee, S. (2004). The influence of metacognitive skills on learner's memory of information in a hypermedia environment. Journal of Educational Computing Research, 31(7), 77-93. http://dx.doi.org/10.2190/JE7W-VL6W-RNYF-RD4M

Shaffer, D. (2002). Developmental psychology: Childhood and adolescence. (6th ed.) Belmont, CA: Wadsworth.

Shamir, A., \& Korat, O. (2006). How to select CD-ROM story books for young children: The teacher's role. The Reading Teacher, 59(6), 532-543. http://dx.doi.org/10.1598/RT.59.6.3

$\mathrm{Su}, \mathrm{Y}-\mathrm{F} .$, \& Samuels, S.J. (2010). Developmental changes in character-complexity and word-length effects when reading Chinese script. Reading and Writing, 23, 1085-1108. http://dx.doi.org/10.1007/s11145-009-9197-3

Wang, C., Hung, L., Chang, Y., \& Chen, H. (2008). Number of characters school students know from grade 1 to 9. Bulletin of Educational Psychology, 39(4), 555-568.

Wang, P.-Y., \& Yang, H.-C. (2014). The impact of e-book interactivity design on children's learning of character recognition. Interactive Learning Environment. http://dx.doi.org/10.1080/10494820.2014.917112 